Çukurova Üniversitesi Mühendislik Mimarlık Fakültesi Dergisi, 35(1), ss. 173-182, Mart 2020

Çukurova University Journal of the Faculty of Engineering and Architecture, 35(1), pp. 173-182, March 2020

\title{
Yenilenebilir Enerji Kaynaklarında Sürekliliği Sağlamak için Optimum Enerji Karışımının Belirlenmesi: Kahramanmaraş Bölgesinde Bir Uygulama
}

\author{
İsrafil KARADÖL ${ }^{* 1}$, Ceyhun YILDIZ ${ }^{2}$, Hakan AÇIKGÖZ ${ }^{3}$, Mustafa ŞEKKELİ ${ }^{4}$ \\ ${ }^{1}$ Kilis 7 Aralı Üniversitesi, Elektrik-Elektronik Mühendisliği, Elektrik Bölümü, Kilis

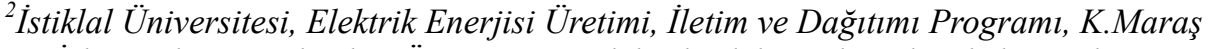 \\ ${ }^{3}$ G.Antep İslam Bilim ve Teknoloji Üniversitesi, Elektrik-Elektronik Mühendisliği Bölümü, G.Antep \\ ${ }^{4}$ K.Maraş Sütçü İmam Üniversitesi, Elektrik-Elektronik Mühendisliği Bölümü, K.Maraş
}

Geliş tarihi: $18.02 .2020 \quad$ Kabul tarihi: 15.05 .2020

$\ddot{\mathbf{O} z}$

Yenilenebilir enerji santral (YES) üretimleri, iklim koşullarına bağlı olarak sürekli değişmektedir. Bu sürekli değişim şebekenin güç-frekans dengesi üzerinde bozucu etkilere neden olmaktadır. YES üretim değişimlerinin etkilerini azaltmanın üç farklı yolu vardır: Şebeke sistemlerini birbirine bağlamak, enerjiyi depolamak ve enerji kaynakları arasındaki zamansal tamamlamadan faydalanmaktır. Yapılan bu çalışmada üç farklı yenilenebilir enerji kaynağı arasındaki zamansal tamamlamadan faydalanılarak daha kararlı bir enerji karışımı elde edilmiştir. Çalışma Kahramanmaraş ili için gerçekleştirilmiştir. Hesaplamaların gerçeğe yakın olması amacıyla ilde işletilmekte olan üç farklı YES'ten (hidroelektrik santral (HES), güneş enerjisi santrali (GES) ve rüzgar e (RES)) gerçek üretim verileri alınmıştır. Yapılan hesaplamalar sonucunda incelenen HES, GES ve RES nerjisi santrali üretimlerinin optimum karışım oranları sırasıyla $\% 14, \% 56$ ve $\% 30$ olarak elde edilmiştir. Kahramanmaraş İli’nde bu oranlar dikkate alınarak tesisler kurulursa üretimin daha kararlı bir hale geleceği görülmüştür. Bu durumda YES üretimlerinin geleneksel şebeke sistemlerinin, güç-frekans dengesi üzerindeki bozucu etkisi de azalacaktır.

Anahtar Kelimeler: Optimum enerji karışımı, Yenilenebilir enerji kaynakları, Enerji üretim kararlılığı

\section{Determination of the Optimal Energy Mix to Ensure Continuity in Renewable Energy Sources: an Application in the Kahramanmaraş Region}

\begin{abstract}
Renewable energy power plant (REPP) generations varies continuously depending on climatic conditions. This continuous change causes disruptive effects on the frequency-power balance of the grid. There are three different ways to mitigate these effects of REPP generation changes: Connecting grid systems, storing energy and using the temporal completion between energy sources. In this study, a more stable energy mix was obtained by using the temporal completion between three different renewable energy sources. The study was carried out for Kahramanmaraş province. Data were obtained from three different (REPP) (hydroelectric power plant (HEPP), solar power plant (SPP) and wind power plant (WPP)
\end{abstract}

*Sorumlu (Corresponding author) yazar: İsrafil KARADÖL, israfilkaradol@kilis.edu.tr 
Yenilenebilir Enerji Kaynaklarında Sürekliliği Să̆lamak için Optimum Enerji Karışımının Belirlenmesi: Kahramanmaraş Bölgesinde Bir Uygulama

operated in the province to make the calculations more realistic. As a result of the calculations, optimum mix rates of investigated HEPP, SPP and WPP generations were obtained as 14\%, 56\% and 30\% respectively. In Kahramanmaraş province, it is seen that if the plants are installed by taking these rates into consideration, production will become more stable. In this case, the disruptive effect of REPP generations on the frequency-power balance of traditional grid systems will also be reduced.

Keywords: Optimal energy mix, Renewable energy resources, Energy generation stability

\section{GíRiş}

Teknolojik gelişmeler günden güne hayatımızın her alanına daha çok etki etmektedir. Otomobil, giyim, spor, ev aletleri vb. birçok alandaki gelişmeler insanoğlunun memnuniyet noktasını daha yukarılara taşımıştır [1]. Gelişen bu teknoloji ile beraber teknolojinin kullanım alanlarının artması, enerjiye olan talebi de arttırmıştır. Bu nedenlerden dolayı geleneksel enerji kaynaklarının (kömür, petrol, linyit vb.) kullanımı da artmıştır [2]. Geleneksel enerji kaynaklarının fazla miktarlarda kullanımı bu kaynakların tükenme sorununu ön plana taşımıştır [3]. Ayrıca bu kaynakların aşırı kullanımı çevre kirliliğine, sera gazlarının artmasına ve enerji kaynağının ithal edilmesinden dolayı dışa bağımlılığın artışı gibi birçok soruna neden olmaktadır [4]. Tüm bu nedenlerden dolayı devletler geleneksel enerji kaynaklarının yerini alabilecek alternatif enerji kaynaklarına (su, güneş, rüzgar, vb.) yönelmişlerdir. $\mathrm{Bu}$ kaynakların sürdürülebilir olması ve devletlerin sınırları içerisinde yer alması, ülkelerin dışa bağımlılığını azaltmasından dolayı bu kaynakların önemini daha da arttırmıştır [5]. Ayrıca bu kaynakların geleneksel enerji kaynaklarına kıyasla, çevresel etkileri daha azdır [6].

Yenilenebilir enerji kaynakları (YEK) arasında en fazla kullanılanlar hidroelektrik, rüzgâr ve güneş enerjileridir. Son yıllarda bu kaynakların etkin kullanımı konusunda ülkemizde de hızlı gelişmeler olduğu görülmektedir [7]. $\mathrm{Bu}$ kaynaklardan üretilen elektriksel enerji, geleneksel şebeke sistemlerinin esnekliği ve güvenliği açısından bozucu etkiler oluşturmaktadır. Bu bozucu etki, YEK tesislerindeki üretimlerin iklimsel koşullara bağlı olarak anlık değişimler göstermesinden kaynaklanmaktadır.
Konu ile ilgili yapılan literatür taramasında bazı çalışmaların öne çıktığı görülmüştür. $\mathrm{Wu}$ ve arkadaşları; GES tesislerinin geleneksel bir şebekeye, şebeke kurulu gücünün $\% 5, \% 10, \% 20$ ve $\% 30$ oranlarında dahil edilmesi durumunda oluşacak etkiyi incelemişlerdir. Herhangi bir arıza durumunda GES tesis kurulu güç oranı ile şebeke frekansındaki bozulmanın paralellik gösterdiği sonucuna ulaşılmıştır [8]. Eftekharnejad ve arkadaşları; çalışmalarında kurulu gücü $21 \mathrm{GW}$ ve talep gücü $13 \mathrm{GW}$ olan geleneksel bir şebeke sistemi üzerinde incelemeler yapmışlardır. $\mathrm{Bu}$ şebeke sistemine 20 farklı oranda GES tesisi dahil ederek, şebekedeki herhangi bir arıza sonucunda frekansin bozulmasını bu oranlara göre değerlendirmişlerdir. Değerlendirmeler sonucunda GES kurulu güç oranı arttıkça, şebekenin frekans bozukluğundaki toparlanmanın da geciktiği görülmüştür [9]. Vong ve arkadaşları; yaptıkları çalışmada farklı GES kurulu güçlerinde oluşan kısa ve uzun süreli şebeke arızalarındaki frekans bozulmalarını incelemişlerdir. GES kurulu gücünün artmasıyla şebekenin frekans kontrolünün zorlaştığı sonucuna ulaşmışlardır [10]. Demirol ve Demirol yaptıkları çalışmada benzetim programları yardımıyla RES dahil edilen geleneksel bir şebeke modeli oluşturmuşlardır. $\mathrm{Bu}$ model üzerinden geleneksel şebeke sistemine RES eklenerek herhangi bir arıza durumunda şebekenin frekans tepkisini, aktif ve reaktif güç kontrol performanslarını incelemişlerdir. İnceleme sonucunda geleneksel bir şebekedeki YEK tesisi sayısının artmasi durumunda mevcut enerji santrallerinin frekans kontrol rezervlerinin artırılmasına ihtiyaç duyulabileceği görülmüştür [11]. Wang ve arkadaşlarının çalışmalarında, GES ve RES üretimlerinin şebeke üzerindeki etkileri incelenmiştir. İncelemeler sonucunda şebekedeki frekans kararlılığının sağlanabilmesi için şebekenin kurulu gücüne göre belirli bir oranda GES ve RES dahil edilebileceği sonucuna 
ulaşmışlardır. Bu oranın üzerinde GES ve RES eklenmesi durumunda ise GES ve RES üretimine bağlı olarak şebeke frekansında bozulmalar meydana geldiğini belirtmişlerdir [12]. $\mathrm{Bu}$ çalışmalarında YEK'lerin geleneksel şebeke sistemleri üzerindeki bozucu etkileri gösterilmiştir. Literatürdeki bazı çalışmalar bu bozucu etkinin farklı YEK'ler arasındaki zamansal tamamlamadan faydalanılarak azaltılabileceğini ortaya koymuştur. yönünü ve büyüklüğünü belirlemek amacıyla korelasyon analizi yapılmışlardır. RES ve GES üretimlerinin zamansal tamamlama oranlarının konuma göre değişkenlik gösterdiği sonucuna ulaşmışlardır [14]. Karadöl ve arkadaşları tarafından yapılan çalışmada Malatya ilinde yer alan HES üretimleri ile Pvsyst (Photovoltaic System) yazılımı üzerinden elde edilmiş GES üretimleri arasındaki ilişkinin yönü ve büyüklüğü belirlenmiştir. Daha sonra bu iki tesis üretimlerinin daha kararlı olması amaciyla, tesisler arasındaki optimum karışım oranı belirlenmiştir [15]. Schmidt ve arkadaşları yaptıkları çalışmada YEK'ler ile Brezilya'nın enerji talebini karşılayabilecek optimum enerji karışım oranlarını araştırmışlardır. Bu amaçla benzetim programları üzerinde Brezilya'nın faklı konumlarında farklı iklimler için GES ve RES'leri modellemişlerdir. $\mathrm{Bu}$ modellemelerde, elde edilen veriler ile mevcut akarsu verileri birleştirilmiştir. Santrallerin kurulduğu bölgelerde enerji talebini sürekli olarak karşılayabilmek için pompaj depolamalı HES'lere ihtiyaç duyulduğu ortaya koyulmuştur [16]. Literatür taraması sonucunda konu ile ilgili çok az sayıda çalışma yapıldığı ve Türkiye'de ise sadece Karadöl ve arkadaşları tarafindan, Malatya ili için bir çalışma yapılmış olduğu görülmüştür. $\mathrm{Bu}$ çalışmada da gerçek bir HES üretimleri ile Pvsyst yazılımından elde edilen üretimler incelenmiştir. YEK potansiyeli yüksek bir ülke olan Türkiye için bu tip çalışmaların gerçek üretim değerleri kullanılarak farklı bölgeler için de yapılmasına ihtiyaç olduğu açıktır.

Bu çalışmada, Kahramanmaraş bölgesindeki farklı YEK üretimlerinin zamansal tamamlamasından faydalanılarak enerji üretiminde sürekliliğin sağlanması amaçlanmıştır. Bu kapsamda öncelikle
Dos Anjos ve arkadaşları yaptıkları çalıșmada GES ve RES üretimleri arasındaki korelasyon analizini incelemişlerdir. $\mathrm{Bu}$ incelemeler sonucunda bu iki kaynak arasındaki ilişkinin yönünü ve büyüklüğünü belirleyerek kaynaklar arasındaki zamansal tamamlamayı göstermişlerdir [13]. Silva ve arkadaşları çalışmalarında 12 adet RES ve 12 adet GES üretimleri arasındaki ilişkiyi incelemişlerdir. Tesisler arasındaki ilişkinin bölgedeki YEK üretimlerinin temsil eden birer HES, GES ve RES belirlenmiștir. HES, GES ve RES kurulu güçleri sırasıyla $8 \mathrm{MW}, 1 \mathrm{MW}$ ve 27,5 MW'dır. Belirlenen tesislerin kurulu güçlerinin farklı olmasından dolayı üretim değerleri tesislerin kurulu güçlerine bölünerek per-unit'e (pu) çevrilmiştir. Daha sonra tesislerin zamansal tamamlamasından faydalanabilmek amacıyla HES, GES ve RES üretimleri arasındaki optimum karışım oranı belirlenmiştir. Bu optimum karışım oranı HES, GES ve RES için sırasıyla \%14, \%56 ve $\% 30$ olarak elde edilmiştir. Kahramanmaraş bölgesinde bu oranlarda tesisler kurulursa YEK üretimlerinin kararlı bir hale gelebileceği görülmüştür. $\mathrm{Bu}$ çalışmanın literatüre katkısı, ilk defa Türkiye'de gerçek tesis üretimleri kullanılarak üç farklı YEK tesisinin enerji üretiminde sürekliliği sağlayacak bir optimum enerji karışımının belirlenmesi olmuştur.

$\mathrm{Bu}$ makale dört bölümden oluşmaktadır. Birinci bölümde, yapılan çalışma hakkında genel bilgiler ve literatürde yer alan önceki çalışmaların özetleri verilmiştir. İkinci bölümde, çalışmada incelenen tesis konumları ve tesislere ait teknik özellikler anlatılmıştır. Ayrıca optimum enerji karışımı hesabında kullanılan yöntem de bu bölümde anlatılmıştır. Üçüncü bölümde, yapılan araștırmalarda sonucunda elde edilen bulgular paylaşılmıştır. Dördüncü bölümde ise elde edilen bulgular yorumlanmıştır.

\section{MATERYAL VE METOT}

\section{1. İncelenen Tesisler}

Yapılan bu çalışmada Kahramanmaraş'ta işletilmekte olan üç farklı YEK tesisi üretimi 
Yenilenebilir Enerji Kaynaklarında Sürekliliği Să̆lamak için Optimum Enerji Karlşımının Belirlenmesi: Kahramanmaraş Bölgesinde Bir Uygulama

arasındaki optimum karışım belirlenmeye çalışılmıştır. İncelenen tesislerin konumları Şekil 1'deki harita üzerinde gösterilmiştir. Gösterilen konumlardaki HES, GES ve RES sırasıyla Kahramanmaraş'ın Afşin, Pazarcık ve Andırın ilçelerinde yer almaktadır. Ayrıca Şekil 2'de incelenen tesislerin 2018 y1lına ait saatlik üretimleri verilmiştir. Bu tesisler bölgedeki YEK rejimlerini temsil etmesi amaciyla pilot olarak seçilmiştir. İlerleyen alt bölümlerde tesislere ilişkin bazı teknik detaylar verilmiştir.

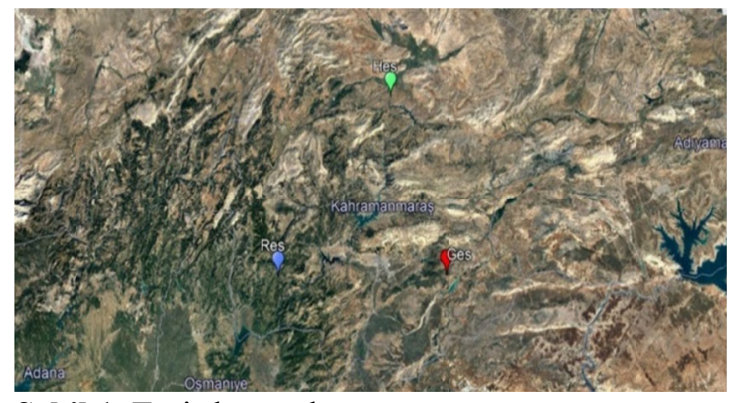

Şekil 1. Tesis konumları

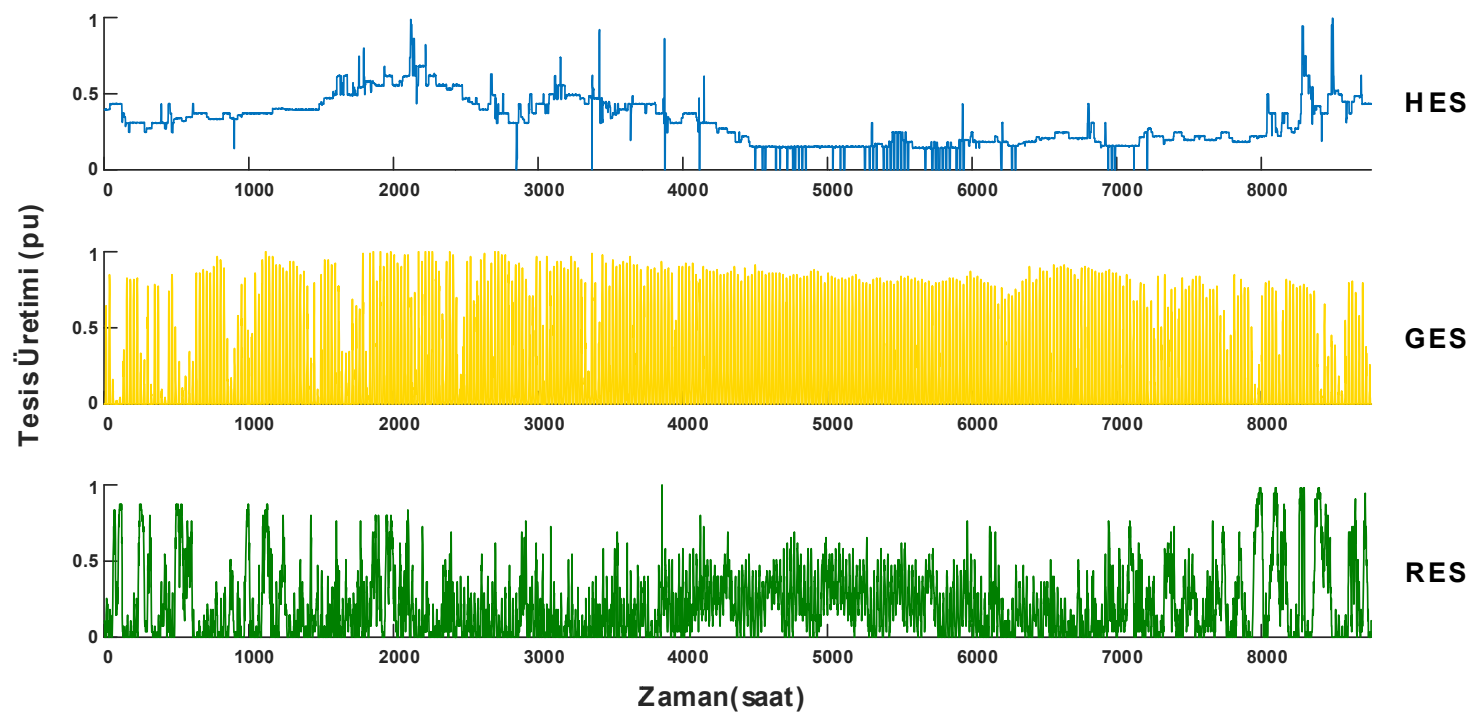

Şekil 2. Tesislerin 2018 yılına ait saatlik üretimler

\subsubsection{Hidroelektrik Santral}

HES'ler olgun teknolojileri ve çevre dostu olmaları sebebiyle yaygın olarak kullanılan enerji dönüşüm sistemleridir. HES'ler kendi arasında barajlı ve nehir tipi olmak üzere iki guruba ayrılmaktadır. Barajlı HES üretimleri talep yüke göre ayarlanabilmektedir [17]. $\mathrm{Bu}$ sayede barajlı HES'ler şebeke üzerinde herhangi bir bozucu etkiye neden olmamaktadır. Fakat nehir tipi HES'ler ise suyun akış debisine bağımlı olarak enerji üretmektedirler [18,19]. Su akışının kontrol edilememesinden dolay bu tip tesis üretimlerindeki kararsızlık, şebekenin esnekliğini ve güvenliğini olumsuz yönde etkilemektedir [20-23].
Yapılan bu çalışmada, Kahramanmaraş/Elbistan ilçesi, Ceyhan Nehri kolu üzerine kurulu bir nehir tipi HES incelenmiștir. İncelenen tesisi ait görüntü Şekil 3'te verilmiştir. Ayrıca bu tesise ait bazı teknik özellikler Çizelge 1'de verilmiştir.

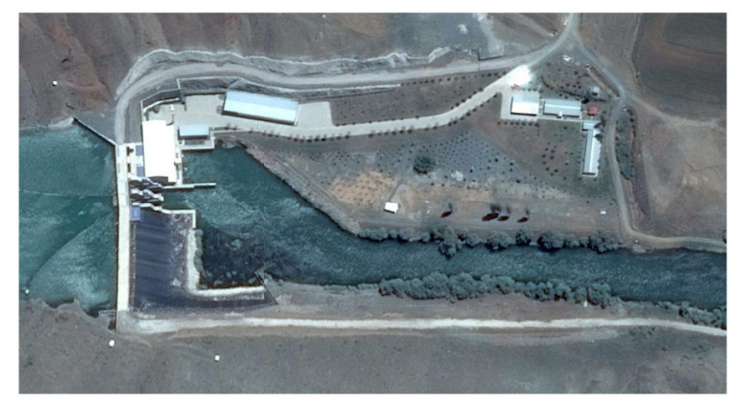

Şekil 3. Hidroelektrik santral 
Çizelge 1. HES teknik özellikleri

\begin{tabular}{|l|c|}
\hline Tesis Özellikler & 2016 \\
\hline Kurulum Yilı & 2 \\
\hline Türbin Adeti & Kaplan \\
\hline Türbin Tipi & $23,1 \mathrm{~m}$ \\
\hline Düşü Yüksekliği (m) & 8 \\
\hline Kurulu Güç (MW) & 27,6 \\
\hline Senelik Üretim (GWh)
\end{tabular}

\subsubsection{Güneş Enerjisi Santrali}

Gelişen dünyada, nüfusun artmasıyla beraber sanayi ve teknolojide enerjiye duyulan ihtiyaçta giderek artmaktadır. [24,25]. Artan enerji ihtiyacını geleneksel enerji kaynaklarından (kömür, petrol, vs.) karşılamak hem sürdürülebilirlik açısından hem de çevre açısından birçok sorunu beraberinde getirmektedir $[7,26]$. Bu nedenlerden dolayı ülkeler geleneksel enerji kaynaklarının yerini alabilecek ve çevreye daha az zarar verecek alternatif enerji kaynaklara yönelmişlerdir. Alternatif enerji kaynakları arasında en büyük potansiyele sahip enerji kaynağı güneş enerjisidir. Aynı zamanda güneş enerjisinin sürdürülebilir ve temiz olması bu enerji kaynağının önemini daha da artırmıştır [27]. Tüm bu nedenlerden dolayı ülkeler artan enerji taleplerini, güneşten karşılamaya yönelmişlerdir. Fakat güneş enerjisinden üretilen elektriksell enerjinin şebekeye aktarılması esnasinda bazı sorunlar ortaya çıkmaktadır. GES üretimlerini etkileyen meteorolojik parametrelerin ani şekilde değişkenlik göstermesi tesis üretimlerinde ani değişimlere neden olmaktadır. Enerji üretimindeki ani düşüşler ve yükselmeler geleneksel şebeke sistemleri üzerinde bozucu etkilere neden olmaktadir.

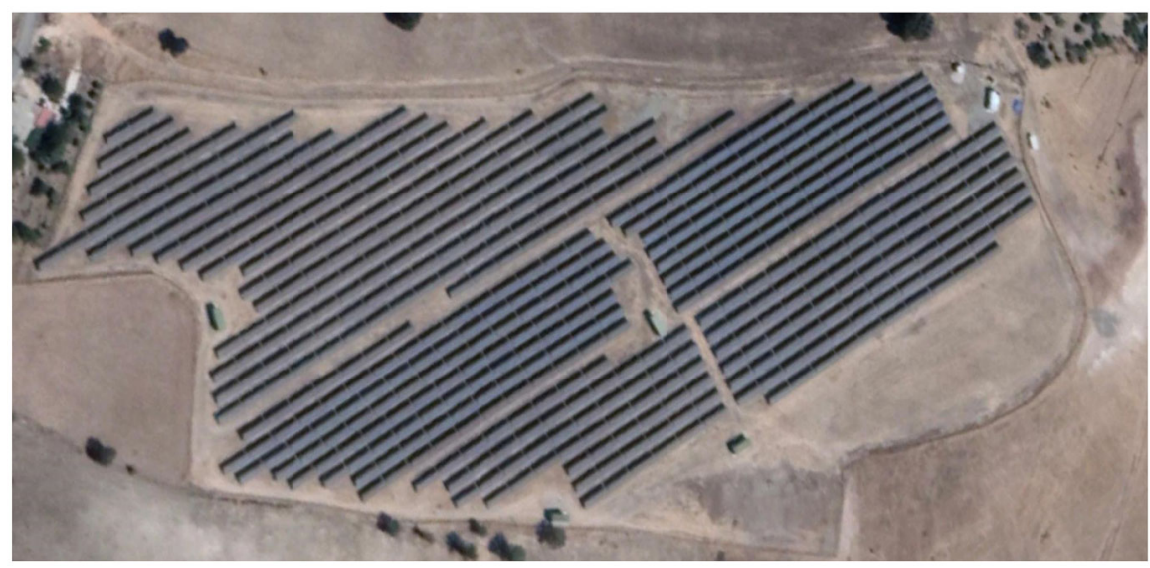

Şekil 4. Güneş enerjisi santrali

Yapılan bu çalışmada incelenen GES konum olarak Kahramanmaraş/Pazarcık İlçesi'nde bulunmaktadır. Bu tesisi ait görüntü Şekil 4'te verilmiştir. Ayrıca tesise ait teknik özellikler Çizelge 2'de özetlenmiştir. Tüm bu teknik özelliklere ek olarak panellerin güneşlenme süresini en üst sevide tutabilmek amaciyla, panellerin yüzeyle yaptığı açı $33^{\circ}$ 'dir ve arazi yüzeyinden dolayı ise panellerin azimut açısı $-7^{\mathrm{o}}$ dir.
Çizelge 2. GES teknik özellikleri

\begin{tabular}{|l|c|}
\hline Özellik & Değer veya Tür \\
\hline Panel türü & P'olikristal Silikon \\
\hline Panel markas1 & Yinglli Solar YL260P-35b \\
\hline Panel çı1ş gücü (W) & 260 \\
\hline Panel Adeti & 3960 \\
\hline Evirici markas1 & ABB \\
\hline Evirici modeli & TRIO-27,6-TL-OUTD \\
\hline $\begin{array}{l}\text { Evirici nominal çık1ş } \\
\text { gücü (W) }\end{array}$ & 27600 \\
\hline $\begin{array}{l}\text { Evirici maksimum Çık1ş } \\
\text { gücü (W) }\end{array}$ & 30000 \\
\hline Evirici adeti & 33 \\
\hline
\end{tabular}


Yenilenebilir Enerji Kaynaklarında Sürekliliği Să̆lamak için Optimum Enerji Karlşımının Belirlenmesi: Kahramanmaraş Bölgesinde Bir Uygulama

\subsubsection{Rüzgar Enerji Santrali}

Rüzgâr enerjisi, yenilenebilir enerji kaynakları arasında ticari anlamda en ekonomik enerji türüdür [28]. Rüzgâr enerjisinin diğer yenilebilir enerji kaynaklarına kıyasla daha ekonomik olmasının doğal sonucu olarak rüzgar enerjisi sektörü hıla gelişmiş ve büyümüştür. Türkiye'de, rüzgar enerjisi yarışındaki yerini alarak bu sektör için gerekli atılımları yapmıştır. 2015 yılında RES kurulu gücü 4,503 MW iken 2018'de RES kurulu gücü 6,620 MW'dır [29]. Rüzgâr enerji sektöründe bu denli büyük gelişmeler yaşanmasına rağmen bu enerji kaynağının geleneksel şebeke sistemlerine dâhil edilmesi şebekenin esnekliği ve güvenliği açısından bazı sorunlara neden olmaktadır. Çünkü rüzgâr enerjisindeki ani üretim değişimleri kontrol edilememektedir. Bu durum şebekenin güç-frekans dengesini bozmaktadır. Yapılan bu çalışmada incelenen RES, Kahramanmaraş/Andırın İlçesi'ndedir. Bu tesise ait görüntü Şekil 5'te verilmiştir. Ayrıca bu tesise ait teknik özellikler Çizelge 3'te özetlenmiştir.

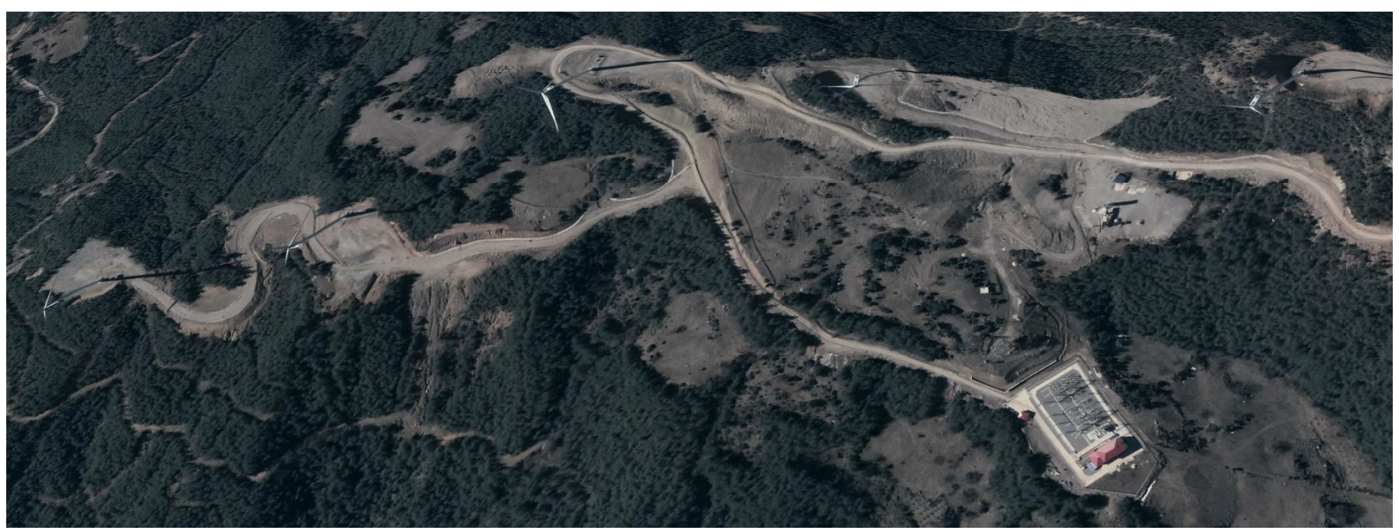

Şekil 5. Rüzgâr enerjisi santrali

Çizelge 3. RES teknik özellikleri

\begin{tabular}{|l|c|}
\hline \multicolumn{2}{|l|}{ Tesis özellikler } \\
\hline Kurulum yılı & 2015 \\
\hline Türbin adeti & 12 \\
\hline Türbin markası & Nordex \\
\hline Türbin çıkış gücü (MWm) & 2,4 \\
\hline Kanat sayısı & 3 \\
\hline Kule yüksekliği (m) & 91 \\
\hline Kanat çapı (m) & 117 \\
\hline Süpürme alanı (m²) & 10715 \\
\hline Tesis kurulu gücü (MWm) & 28,8 \\
\hline Senelik üretim $(\mathrm{GWh})$ & 70,0 \\
\hline
\end{tabular}

\subsection{Optimum Enerji Karışımının Belirlenmesi}

$\mathrm{Bu}$ çalışmada yapılan hesaplamalarda Kahramanmaraş’ta faaliyet gösteren üç farklı YEK tesisinin 2018 yılına ait saatlik üretimleri kullanılmıştır. Bu tesislerin Ş'ekil 2, Şekil 3 ve Şekil 4'teki yıllık üretim grafiklerini incelediğimizde kararsız bir üretime sahip oldukları görülmektedir. HES yıllık üretimine baktığımızda kış ve ilkbahar aylarında ortalama olarak 0,4 pu civarında üretim gerçekleşirken, yaz ve sonbahar aylarında ise bu üretimin ortalama 0,2 $\mathrm{pu}$ ve altındaki değerlerde üretimler gerçekleşmiştir. GES yıllık üretimlerini incelediğimizde, kış ve ilkbahar aylarındaki üretimlerde dalgalanmalar oldluğu görülmektedir. Fakat yaz ve son bahar aylarındaki üretimlerde ise daha az değişimler gerçekleşmiştir. RES yıllık üretimini incelediğimizde ise ilkbahar, sonbahar ve kış aylarında çok fazla dalgalanma gösterirken, yaz aylarında üretimin çok fazla değișkenlik göstermediği görülmektedir. Sonuç olarak bu üç tip tesis üretimlerinin zamana bağlı olarak değișen kararsız bir yapıda olduğu görülmüştür. Tesis 
üretimlerindeki bu değişkenlik ve kararsızlık geleneksel şebeke sistemlerindeki güç-frekans dengesi üzerinde bozucu bir etkiye neden olmaktadır.

HES, GES ve RES için optimum enerji karıșım oranı belirlenerek, bu tesislerin üretimlerindeki kararsızlığın ve dengesizliğin minimum seviyeye indirgenmesi amaçlanmaktadır. HES, GES, RES ve $\mathrm{P}_{c ̧ ı \mathrm{k}}$ değerlerindeki üretim kararlılığını belirlemek amaciyla üretimlerin standart sapmaları incelenmiştir. Standart sapma, olasılık teorisi ve istatiksel analizlerde kullanılan sayısal verilerin veya değişkenlerin, ortalama değere ne kadar uzaklıkta olduğunu gösteren bir ölçüdür. Bir başka ifadeyle, değişkenlerin ne genişlikte bir aralıkta dağıldığını gösteren sayısal bir ifadedir. Yani herhangi bir veri setinin standart sapma değeri küçükse (sıfıra yakınsa) bu verilerin çok fazla değişkenlik göstermediğini (homojen dağıldığını) ifade etmektedir. Fakat standart sapma değeri büyükse (bire yakınsa) bu veri setinin çok fazla değişkenlik gösterdiğini (heterojen dağıldığını) ifade etmektedir. Standart sapmanın matematiksel olarak ifadesi Eşitlik 1'de verilmiştir. Eşitlik 1'deki n toplam terim sayısını ve xi ise her bir terimi ifade etmektedir.

$\sigma=\sqrt{\frac{1}{(n-1)} \sum\left\{x_{i}^{2}-\left(\frac{1}{n} \sum x_{i}\right)^{2}\right\}}$

Tesisler arasındaki optimum enerji karışım oranını belirlemek için ise Eşitlik 2 kullanılmıştır [27,30]. Eşitlikte kullanılan $\mathrm{P}_{c ̧ \mathrm{k}}$ değeri RES, HES ve GES karışımları sonucunda ortaya çıkan üretimi ifade etmektedir.

$$
P_{\xi l k}=\{\alpha \cdot R E S+(1-\alpha) \cdot(\beta \cdot G E S+(1-\beta) \cdot H E S)\}
$$

Eşitlik 2'de verilen $\alpha$ ve $\beta$ parametreleri, 0 ile 1 aralığında değiştirilerek, 10201 adet $P_{c ̧ ı}$ değer vektörleri elde edilmiştir. $\alpha$ ve $\beta$ parametrelerinin değişim duyarlılığı 0,01 olarak seçilmiştir [27], [30]. $\mathrm{P}_{c \mathrm{clk}}$ denklemindeki her bir tesis katsayısı optimum $\alpha$ ve $\beta$ parametreleri eşitlikte yerine yazılarak elde edilmiştir. Bu durumda RES, GES ve HES katsayıları sirasıyla $\alpha, \quad(1-\alpha) . \beta$ ve
(1- $\alpha) .(1-\beta)$ olmuştur. $\mathrm{Bu}$ katsayılar tesislerin optimum karışımdaki yüzdelik paylarını vermektedir.

\section{ARAŞTIRMA SONUÇLARI VE TARTIŞMA}

\subsection{Optimal Enerji Karışımı}

HES, GES ve RES tesisleri arasındaki optimum enerji karışım oranının belirlenmesi amacıyla, MATLAB programında Eşitlik 2'deki $\alpha$ ve $\beta$ parametrelerinin tüm değerleri için üç boyutlu (101x101x8760 değerden oluşan) $\mathrm{P}_{c ̧ 1 k}$ vektörleri elde edilmiştir. Elde edilen $\mathrm{P}_{\text {çık }}$ vektöründeki, ilk iki boyut $(101 \times 101) \alpha$ ve $\beta$ 'nın aldığı değerleri $((0<\alpha<1),(0<\beta<1))$ ve 8760 vektörü ise tesislerin saatlik üretim verilerini ifade etmektedir. $P_{c ̧, k}$ vektörü elde edilirken $\alpha$ ve $\beta$ değerleri 0,01 hassasiyetle artırılarak, 0'dan 1'e kadar tüm değerler için $\mathrm{P}_{\text {çk }}$ vektörleri elde edilmiştir. Elde edilen bu vektörün 10201 adet sonucu olup, bu sonuçların tek tek incelenmesi mümkün değildir. $\mathrm{Bu}$ nedenle, en kararlı üretime sahip $\mathrm{P}_{\text {çık }}$ vektörünü bulmak için $\mathrm{P}_{\text {çık }}$ vektörünün standart sapmaları incelenmiştir [27,30-32]. Bu vektörlerin standart sapmalarının $\alpha$ ve $\beta$ parametrelerine göre değişimi Şekil 6'da verilmiştir. Şekil 6'da gösterilen $\mathrm{P}_{\text {çik }}$ vektörüne ait tüm sonuçların standart sapmaları incelendiğinde en yüksek değerin 0,3043 (kırmızı) ve en düşük değerin 0,1132 (lacivert) olduğu görülmüştür. $P_{c ̧ 1 k}$ vektörleri arasında en küçük standart sapmaya sahip olan vektörün, $\alpha$ ve $\beta$ parametrelerinin sirasiyla 0,30 ve 0,80 olmas1 durumunda elde edildiği tespit edilmiştir. Elde edilen en küçük standart sapmaya sahip $P_{c ̧ ı k}$ vektörünün yıllık tesis üretimi Şekil 7'de gösterilmiştir. Ayrıca her bir tesise ait üretimlerin ve optimum enerji karışımın üretiminin standart sapmaları Çizelge 4'te verilmiştir. Bölgede kurulu HES üretimlerinin standart sapmasının küçük olması, HES üretiminin diğer kaynaklara oranla daha kararlı bir yapıya olduğunu göstermektedir. Fakat çözümü gerçekleştirilen optimum karışım denkleminin sonucunda daha küçük standart sapmaya sahip bir üretim çıktısı elde edilmiştir. 
Yenilenebilir Enerji Kaynaklarında Sürekliliği Să̆lamak için Optimum Enerji Karlşımının Belirlenmesi: Kahramanmaraş Bölgesinde Bir Uygulama

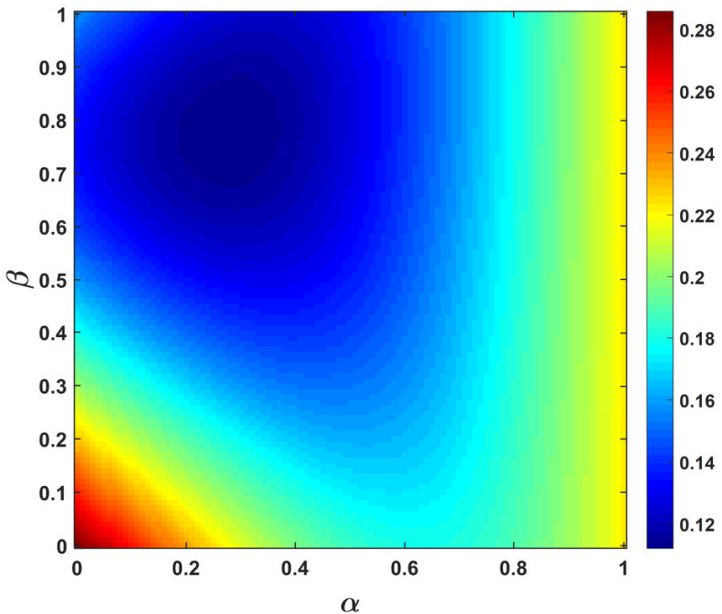

Şekil 6. $P_{c ̧ l k}$ standart sapma grafiği
Çizelge 4. HES, GES, RES ve optimum enerji karışımının standart sapma değerleri

\begin{tabular}{|l|c|c|c|c|}
\hline Tesisler & HES & GES & RES & $\begin{array}{c}\text { Optimum } \\
\text { Karıșim }\end{array}$ \\
\hline $\begin{array}{l}\text { Standart } \\
\text { Sapma }\end{array}$ & 0,1567 & 0,3043 & 0,2210 & 0,1132 \\
\hline
\end{tabular}

Bu çalışmadan elde edilen sonuçlar ışı̆̆ında farklı HES, GES ve RES karışımı oranlarının farklı standart sapma değerlerine sahip olduğu görülmüştür. Fakat bu sonuçları bu üç tip tesis üretimleri için genelleştirmek doğru olmayacaktır. Çünkü farklı bölgelerdeki tesislerin üretim karekteristikleri iklimsel özelliklere bağlı olarak değişkenlik göstermektedir. $\mathrm{Bu}$ durum ilgili literatürde alınan sonuçlarda da görülmektedir $[15,27,30]$.

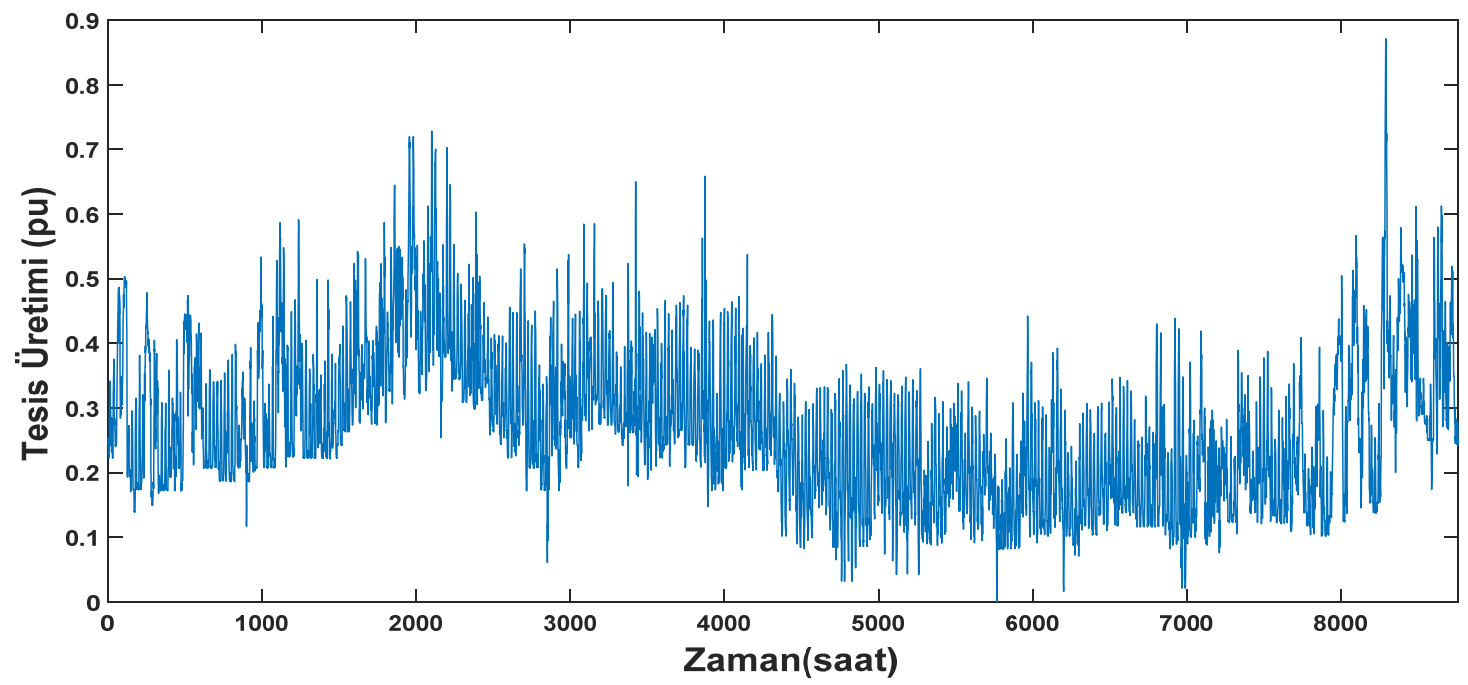

Şekil 7. Optimum enerji karışım üretim çıktısı

\section{SONUC}

YEK tesislerinin şebekeye entegrasyonunda yaşanan sorunların en önemlilerinden biri şebekedeki güç-frekans dengesinin bozulmasıdır. $\mathrm{Bu}$ bozulma YEK tesislerinin süreksiz üretimlerinden kaynaklanmaktadır. Yapılan bu çalışmanın amacı farklı YEK'ler ile beslenen tesis üretimlerinin, belirli oranlar da karıştırılması ile YEK tesislerindeki enerji üretim sürekliliğini sağlamaktır. $\mathrm{Bu}$ kapsamda öncelikle Kahramanmaraş'ta işletilmekte olan üç farklı YEK tesisi (HES, GES, RES) incelenmiştir. İnceleme sonucunda tesis üretimlerinin sürekli olmadığı ve kararsız bir şekilde değişimler gösterdiği görülmüştür. Tesis üretimlerindeki bu kararsızlık, üretimlerin standart sapmaları incelendiğinde daha net görülmektedir. Yapılan hesaplamalar sonucunda HES, GES ve RES üretimlerinin standart sapmaları sirasiyla $0,1567,0,3043$ ve 0,2210 olarak bulunmuştur. Kararsız YEK tesis üretimlerini daha kararlı hale getirebilmek amacıyla tesis üretimleri arasındaki optimum karışım, çalışmada önerilen denklem kullanılarak 

$\begin{array}{ll}\text { hesaplanmıştır. } & \text { Denklemdeki } \alpha \text { ve } \beta \\ \text { parametrelerinin } & \text { tüm değerleri }{ }^{\text {için }} P_{\text {ç } l k}\end{array}$ vektörünün standart sapması incelenmiştir (Şekil 6). $\mathrm{P}_{\text {çık }}$ vektörünün standart sapmasının en küçük olduğu değer, tesis üretimlerinin optimum karışım oranını (en kararlı tesis üretimini) göstermektedir. Yapılan incelemeler sonucunda $\mathrm{P}_{\text {clk }}$ vektöründeki standart sapmanın minimum olduğu $\alpha$ ve $\beta$ değerleri sirasıyla 0,30 ve 0,80 olarak bulunmuştur. Elde edilen $\alpha$ ve $\beta$ değerlerini $\mathrm{P}_{\text {çlk }}$ denklemine yerleştirdiğimizde Kahramanmaraş bölgesinde kurulacak optimum HES, GES ve RES oranları sirasiyla $\% 14, \% 56$ ve $\% 30$ olarak elde edilmiştir. Bölgede bu oranlara sahip HES, GES ve RES kurulması sonucunda elde edilecek üretim grafiği Şekil 7'de verilmiştir. Grafikteki optimum enerji karışım değerlerinin standart sapması 0,1132 olarak bulunmuştur. Elde edilen optimum enerji karışımının, tüm tesis üretimlerine göre daha kararlı olduğu görülmektedir. $\mathrm{Bu}$ durum; farklı bölgelerde kurulabilecek YEK tesisleri arasında optimum enerji karıșım oranı belirlenerek, YEK üretimlerinin geleneksel şebeke sistemleri üzerindeki bozucu etkisinin azaltılabileceğini göstermektedir.

\section{KAYNAKÇA}

1. Şahin, C., Karaçor, M., Özbay, H., 2019. Yenilenebilir Enerji Kaynağı Kurulum Gücü Minimize Katsayısının Belirlenmesi, Eur. J. Sci. Technol., 15, 404-411.

2. Gençoğlu, M.T., 2002. Yenilenebilir Enerji Kaynaklarının Türkiye Açısından Önemi," Fırat Üniversitesi Fen ve Mühendislik Bilim. Derg., 14(2), 57-64.

3. Kayapınar Kaya, S., Dal, M., Aşkın, A., 2019. Türkiye'deki Devlet ve Vakıf Üniversite Kampüslerinin Sürdürülebilir-ekolojik Parametreleri Açısından Karşılaştırılması, Balıkesir Üniversitesi Fen Bilim. Enstitüsü Derg., 21(1), 1-20.

4. Yıldırım, O., Nuri, F.İ., 2018. Yenilenebilir Enerji ve Sürdürülebilir Kalkınma İlişkisi, J. International Banking Econ. Manag. Studies, 1, (1), 105-143.

5. Karadöl, I., Keçecioğlu, Ö.F., Açıkgöz, H., Şekkeli, M., 2017. Kahramanmaraş Bölgesi için Güneş ve Rüzgâr Enerjisi Hibrit Sisteminin İ́ncelenmesi, 20(2), 89-96.

6. Thomaidis, N.S., Santos-Alamillos, F.J., PozoVázquez, D., Usaola-García, J., 2016. Optimal Management of Wind and Solar Energy Resources, Comput. Oper. Res., 66, 284-291.

7. Kılınç, F.Ç., 2015. Güneş Enerjisi, Türkiye'deki Son Durumu ve Üretim Teknolojileri, Mühendis ve Makina, 56(671), 28.

8. Wu, Y.K., Tsai, S.H., Zou, M.Y., 2013. Accommodating High PV Penetration on the Distribution System of Kinmen Island, Energy Power Eng., 05(04), 209-214.

9. Eftekharnejad, S., Heydt, G.T., Vittal, V., 2015. Optimal Generation Dispatch with High Penetration of Photovoltaic Generation, IEEE Trans. Sustain. Energy, 6(3), 1013-1020.

10. Vong, N.M., Pillay, S., Lo, V., 2018. Effect of Solar PV on Frequency Management in New Zealand, 2017 IEEE Innov. Smart Grid Technol. - Asia Smart Grid Smart Community, 1-6.

11. Demirol, M., Demirol, T.N., 2015. Occuring Simulation Model of Grid Connection, Gazi Mühendislik Bilim. Derg., 1(3), 351-368.

12. Wang, Y., Silva, V., Lopez-Botet-Zulueta, M., 2015. Impact of High Penetration of Variable Renewable Generation on Frequency Dynamics in the Continental Europe Interconnected System, IET Renew. Power Gener., 10(1), 10-16.

13. Dos Anjos, P.S., Alves Da Silva, A.S., Stošić, B., Stošić, T., 2015. Long-term Correlations and Cross-correlations in Wind Speed and Solar Radiation Temporal Series from Fernando de Noronha Island, Brazil, Phys. A Stat. Mech. its Appl., 424, 90-96.

14. Cantão, M.P., Bessa, M.R., Bettega, R.D., Detzel, H.M., Lima, J.M., 2017. Evaluation of Hydro-wind Complementarity in the Brazilian Territory by Means of Correlation Maps, Renew. Energy, 101, 1215-1225.

15. Karadöl, İ., Yildiz, C., Keçecioğlu, Ö.F., Şekkeli, M., 2018. Kararsız HES ve GES Üretimlerinin Düzenlenmesi için Optimal Enerji Karışımı Tespiti: Malatya İli Örneği Optimal, Gazi Mühendislik Bilim. Derg., 4(2), 84-90. 
Yenilenebilir Enerji Kaynaklarında Sürekliliği Să̆lamak için Optimum Enerji Karışımının Belirlenmesi: Kahramanmaraş Bölgesinde Bir Uygulama

16. Schmidt, J., Cancella, R., Pereira, A.O., 2016. An Optimal Mix of Solar PV, Wind and Hydro Power for a Low-carbon Electricity Supply in Brazil, Renew. Energy, 85, 137-147.

17. Tekin, M., Keçecioğlu, Ö.F., Erafşar, Ö., Şekkeli, M., 2016. Bir Hidroelektrik Santralin (HES) Elektrik Şebekesindeki Harmonik Oluşumuna Etkisinin İncelenmesi, KSU Mühendislik Bilim. Derg., 19(2), 70-77.

18. Emir, A., Bozkuş, Z., Yanmaz, A.M., 2014. Nehir Tipi Hidroelektrik Santrallerin Bilgisayar Destekli Ön Tasarımı, İMO Tek. Dergi, 6925-6942.

19. Yildiz, C., Şekkeli, M., 2016. Optimal Bidding in Turkey Day Ahead Electricity Market for Wind Energy and Pumped Storage Hydro Power Plant, Pamukkale Univ. Muh. Bilim Derg, 22(5), 361-366.

20. Malkawi, S., Al-Nimr, M., Azizi, D., 2017. A Multi-criteria Optimization Analysis for Jordan's Energy Mix, Energy, 127(13), 680-696.

21. Hong, S., Bradshaw, C.J.A., Brook, B.W., 2013. Evaluating Options for the Future Energy Mix of Japan After the Fukushima Nuclear Crisis, Energy Policy, 56, 418-424.

22. Aslantürk, O., Kiprizlı, G., 2020. The Role of Renewable Energy in Ensuring Energy Security of Supply and Reducing Energyrelated Import, Int. J. Energy Econ. Policy, 10(2), 354-359.

23. Viviescas, C., Lima, L., Diuana, F.A., Vasquez, E., Ludovique, C., Silva, G.N., Huback, V., Magalar, L., Szklo, A., Lucena André F.P., Schaeffer, R., 2019. Contribution of Variable Renewable Energy to Increase Energy Security in Latin America: Complementarity and Climate Change Impacts on Wind and Solar Resources, Renew. Sustain. Energy Rev., 113, 1-1.

24. Kandasamy, C.P., Prabu, P., Niruba, K., 2013. Solar Potential Assessment Using PVSYST Software, 2013 International Conference on Green Computing, Communication and Conservation of Energy (ICGCE), Chennai, 2013, 667-672

25. Prasad, A.A., Taylor, R.A., Kay, M., 2017. Assessment of Solar and Wind Resource Synergy in Australia, Appl. Energy, 190,
354-367.

26. Oktik, Ş., 2015. Fotovoltaik Sektörü Değer Zinciri Türkiye için Firsatlar ve Tehditler Güneş Enerjisi Sanayicileri ve Endüstrisi Derneği, 6. Türkiye Enerj. Zirvesi, 84, 12-13.

27. François, B., Borga, M., Creutin, J.D., Hingray, B., Raynaud, D., Sauterleute, J.F., 2016. Complementarity Between Solar and Hydro Power: Sensitivity Study to Climate Characteristics in Northern-Italy, Renew. Energy, 86, 543-553.

28. Albostan, A., Çekiç, Y., Eren, L., 2013. Rüzgar Enerjisinin Türkiye'nin Enerji Arz Güveliğine Etkisi, Gazi Üniversitesi MühendislikMimarlık Fakültesi Derg., 24(4), 641-649.

29. TEİAŞ 2018, Türkiye'de Elektrik Enerjisi Kurulu Gücü, 1-14.

30. De Oliveira Costa Souza Rosa, C., Costa, K.A., Da Silva Christo, E., Bertahone, P.B., 2017. Complementarity of Hydro, Photovoltaic and Wind Power in Rio de Janeiro State, Sustain., 9(7), 1-12.

31. Liu, G., Zhou, J., Jia, B., He, F., Yang, Y., Sun N., 2019. Advance Short-term Wind Energy Quality Assessment Based on Instantaneous Standard Deviation and Variogram of Wind Speed by a Hybrid Method, Appl. Energy, 238, 643-667.

32. Widén, J., 2011. Correlations Between Largescale Solar and Wind Power in a Future Scenario for Sweden, IEEE Trans. Sustain. Energy, 2(2), 177-184. 